\title{
Os registros de representação semiótica de frações em atividades envolvendo
}

\section{tratamento e conversão}

\section{The registers of semiotic representation of fractions in activities involving treatments and conversions}

\author{
Cristina Martins Paraol \\ Universidade Federal do Rio Grande do Sul (UFRGS) \\ Programa de Pós-Graduação em Ensino de Matemática, Porto Alegre, RS, Brasil \\ cristinaparaool@gmail.com
}

Jeremias Stein Rodriguês

Instituto Federal de Educação, Ciência e Tecnologia de Santa Catarina (IFSC) Campus São José, Florianópolis, SC, Brasil jeremias.stein@ifsc.edu.br

\begin{tabular}{l}
\hline Informações do Artigo \\
\hline CC) 9 (7) \\
\hline Histórico do Artigo \\
Submissão: 26 de maio de 2018. \\
Aceite: 30 de outubro de 2018. \\
\hline
\end{tabular}

Palavras-chave

Representação Semiótica

Ensino de Matemática

Aprendizagem de Matemática

Frações

\begin{abstract}
Resumo
Frações são, de modo geral, temidas pela maior parte dos estudantes em diversos níveis de ensino. Isto pode se dar pelo fato de não haver domínio e compreensão desse objeto, assim como das operações que o envolve. Este artigo é o resultado de uma pesquisa qualitativa voltada à Educação Científica e Tecnológica ${ }^{1}$, na qual buscamos averiguar algumas das dificuldades dos estudantes a respeito da resolução de questões envolvendo frações, tendo como base a Teoria de Registros de Representação Semiótica. Para a coleta de dados, foram aplicadas avaliações diagnósticas acerca de frações e seus registros, decimal e figural, com estudantes do ensino básico e superior da região de Araranguá, Santa Catarina. Concluímos que há grande dificuldade nos procedimentos envolvendo frações, principalmente no registro dos números decimais, e que estas são semelhantes tanto no Ensino Fundamental quanto no Ensino Médio. Constatamos também que estas mesmas dificuldades ainda aparecem no Ensino Superior, mas, como esperado, em proporção muito menor.
\end{abstract}

\section{Abstract}

Fractions are, in general, feared by most of the students in the different educational stages. This may occur because there isn't a complete understanding and comprehension of this object, as well as the operations involving fractions. This paper is the result of a qualitative research in the Scientific and Technological Education ${ }^{2}$ in wich we tried to verify some difficulties of students about the problem resolution involving fractions, based on the Theory of Register of Semiotic Representation. To obtain the data, we applied diagnostic evaluations about fractions and their registers, decimal and in figures, with students if the middle school, high school and graduation of the region of Araranguá, Santa Catarina. We concluded that there are difficulties in the proceedings involving fractions, mainly in the register of decimal numbers, and those are similar in the middle school and high school. We find out that those difficulties still appear in the graduation, bus as expected, in much less proportion.

\footnotetext{
${ }_{1}^{1}$ A pesquisa foi desenvolvida no Curso de Especialização em Educação Científica e Tecnológica, do IFSC, Campus Araranguá, no ano de 2017.

${ }^{2}$ This research was developed in the Specialization Course in Scientific and Technological Education, of the IFSC, Araranguá's Campus, in the year of 2017.
} 


\section{Introdução}

$\mathrm{Na}$ tentativa de amenizar as dificuldades no ensino de Matemática, teorias amparadas por metodologias de ensino vêm surgindo e se desenvolvendo com o passar dos anos, buscando diferentes formas de resolver e compreender o que se observa dentro da sala de aula.

A Teoria de Registros de Representação Semiótica (TRRS), desenvolvida por Raymond Duval, é uma importante teoria que surge no cenário do ensino de Matemática na década de 70 . A teoria tem por intuito abordar como a aprendizagem de um objeto matemático, que é estritamente conceitual, se dá quando utilizamos suas formas de representação para se ter acesso às informações e conteúdos acerca do objeto, ou seja, como o uso dos diferentes registros de representação de um objeto matemático afetam o processo de aprendizagem do estudante.

Assim, demos ênfase a duas atividades cognitivas importantes segundo a teoria: o tratamento e a conversão. Segundo Duval (2008), a coordenação destas atividades cognitivas tem relação direta com o processo de aprendizagem e compreensão de conteúdos referentes ao objeto matemático a elas relacionado. Desta forma, focamos nessas duas atividades cognitivas de maneira a tentar verificar se o domínio do tratamento e da conversão é relevante para a compreensão total, ou parcial, do objeto matemático das frações.

Aqui, vamos focar nas frações, por serem um dos objetos matemáticos estudados no Ensino Fundamental, que é utilizado em diversos momentos do cotidiano, em que se verifica dificuldades. De forma geral, as pessoas conhecem frações e alguns de seus processos; um exemplo desse conhecimento é a divisão para se obter o número decimal. No entanto, é comum o professor de Matemática observar a dificuldade em se conseguir resolver operações simples, como a soma de duas frações, seja dentro ou fora da sala de aula. A dificuldade no uso do objeto matemático das frações é uma vivência em sala de aula e foi esse problema que nos levou a desenvolver esta pesquisa, de forma a verificar como a teoria de Duval confirma a dificuldade observada dentro e fora da sala de aula.

Desta forma, este artigo apresenta uma pesquisa sobre o objeto matemático das frações, sob a perspectiva da TRRS. Com intuito de verificar a aprendizagem na resolução de questões envolvendo frações, uma atividade de avaliação diagnóstica foi elaborada e aplicada com estudantes dos ensinos Fundamental, Médio e Superior. Nessa atividade, as questões propostas têm por objetivo verificar os métodos de resolução e também a capacidade de mudar o registro de representação do mesmo objeto, assim como o domínio desses dois processos, domínio esse ligado à compreensão, ou não, do objeto e de seus conteúdos.

Assim, optamos por elaborar duas questões que são o escopo desta pesquisa. A primeira questão, com oito itens, foi pensada com o objetivo de avaliar o algoritmo de resolução dos estudantes; e a segunda questão, com seis itens, foi pensada com o objetivo de avaliar a capacidade de mudança de registro de representação. As duas questões envolvem frações e seus registros. 
A análise será efetuada sobre as respostas apresentadas na avaliação diagnóstica. A verificação será sobre os processos relacionados à manipulação e à mudança de registro que o estudante domina e também sobre os erros observados.

\section{Fundamentação Teórica}

É comum encontrarmos na história do desenvolvimento da Matemática diferentes resoluções para os mesmos problemas matemáticos. Os primeiros grandes matemáticos, como Euclides, utilizavam apenas a geometria para a resolução de problemas. No entanto, com o desenvolvimento da Álgebra, pôde-se apresentar a mesma solução para um problema em mais de uma representação. Assim, evidencia-se que os matemáticos sempre buscaram soluções distintas para o mesmo problema, sendo a busca por diferentes formas de representar a Matemática e sua notação também importantes fatores no desenvolvimento desta ciência (BOYER, 1974).

Duval denomina de objeto matemático os diferentes objetos relacionados aos conteúdos da Matemática, que são inteiramente conceituais, e denomina de representação as diferentes formas de se visualizar ou de representar semioticamente este objeto. Para o autor, o uso das diversas representações de um objeto possibilita a construção gradativa do conhecimento em Matemática. No entanto, Moreti (2002, p. 347) destaca que "do ponto de vista cognitivo, um certo de tipo de informação sobressai mais em uma do que em outra forma" de representar o mesmo objeto. No Quadro 1, mostramos que nas frações podemos usar, por exemplo, as seguintes representações para o mesmo objeto:

Quadro 1 - Exemplo de representações de uma fração.

\begin{tabular}{|c|c|}
\hline Representação & Nome do registro \\
\hline$\frac{1}{2}$ & Fracionário \\
\hline 0,5 & Decimal \\
\hline Uma parte de duas & Língua natural \\
\hline & Figural \\
\hline
\end{tabular}

Fonte: Elaboração dos autores (2017).

Para Duval (2008, p. 13), "É suficiente observar a história do desenvolvimento da matemática, para ver que o desenvolvimento das representações semióticas foi uma condição essencial para a evolução do pensamento matemático".

Segundo Pantoja, Campos e Salcedos (2013), as representações são consideradas uma maneira de expressar o pensamento matemático, visto que os objetos matemáticos não são diretamente perceptíveis ou observáveis sem a utilização de seus registros. Como afirma Duval,

[...] diferentemente dos outros domínios do conhecimento científico, os objetos matemáticos não são jamais acessíveis perceptivelmente ou microscopicamente (microscópio, telescópio, aparelhos de medida, etc.). O acesso aos objetos passa necessariamente por representação semiótica. Além do que, isso explica por que a evolução dos conhecimentos matemáticos conduziu ao desenvolvimento e à diversificação de registros de representação. (DUVAL, 2008, p. 21). 
De acordo com Pantoja, Campos e Salcedos (2013), a TRRS é o emprego de signos como: gráficos, fórmulas, escrita ou figuras, que pertencem a um sistema de registro com significados e funcionamentos, em que a construção do conhecimento ocorre mediante a conversão do objeto de estudo em dois ou mais registros distintos.

A metodologia utilizada por Duval na TRRS para o estudo de um objeto matemático passa por duas etapas de transformação de representações semióticas: tratamento e conversão. Ambos os processos são diferentes porque, enquanto o tratamento é o conjunto de operações efetuadas com o objeto dentro de um registro, a conversão é a troca de registro, ou seja, o processo de mudar a forma de representar um mesmo objeto. Sobre tratamento e conversão, argumenta Durval (2008, p. 16):

- Os tratamentos são transformações de representações dentro de um mesmo registro, por exemplo: efetuar um cálculo ficando estritamente no mesmo sistema de escrita ou de representação.

- As conversões são transformações de representações que consistem em mudança de registro conservando os mesmos objetos denotados: por exemplo, reconhecer a escrita algébrica de uma equação em sua representação gráfica.

No Quadro 2, apresenta-se um exemplo em que se verifica a diferença entre as operações.

Quadro 2 - Exemplo de tratamento e conversão.

\begin{tabular}{|c|c|c|}
\hline $\begin{array}{c}\text { Atividade } \\
\text { cognitiva }\end{array}$ & Operação & Explicação \\
\hline Tratamento & $\frac{1}{2}+\frac{1}{4}=\frac{2+1}{4}=\frac{3}{4}$ & $\begin{array}{c}\text { Na resolução foi realizado o tratamento dentro do mesmo } \\
\text { registro, ou seja, realizou-se a adição das frações. }\end{array}$ \\
\hline Conversão & $\frac{3}{4} \rightarrow 0,75$ & $\begin{array}{c}\text { Na conversão ocorre a mudança de registro, assim } \\
\text { representamos o mesmo termo, agora em sistema semiótico } \\
\text { distinto, como dos números decimais. }\end{array}$ \\
\hline
\end{tabular}

Fonte: Elaboração dos autores (2017).

Os processos de tratamento e conversão são diferentes, porém podem ser realizados de forma sequencial. Observando o Quadro 2, podemos verificar que, geralmente, a conversão de um objeto matemático em um outro registro está ligada à realização de tratamentos dentro do registro de partida, ou de chegada, a fim de obter a resolução do problema.

Para Duval (2008), a capacidade de compreender os conteúdos associados a um objeto matemático está diretamente ligada ao desenvolvimento de conversões entre dois registros de representação do objeto, de forma que isto também esteja relacionado com o tratamento do objeto matemático dentro de cada registro. Assim, o indivíduo, ao realizar tratamento/conversão ou conversão/tratamento, permeia as diferentes representações semióticas de um mesmo objeto matemático. Essa transição entre as representações possibilita a construção do conhecimento matemático. Segundo Duval (2008, p. 14), "A originalidade da atividade matemática está na mobilização simultânea de ao menos dois registros de representação ao mesmo tempo, ou na possibilidade de trocar a todo momento de registro de representação". 
Duval (2012, p. 282) também afirma que "A compreensão (integral) de um conteúdo conceitual repousa sobre a coordenação de ao menos dois registros de representação, e esta coordenação se manifesta pela rapidez e a espontaneidade da atividade cognitiva de conversão".

Para Duval (2008), é a diversidade das representações de um objeto matemático que possibilita a aprendizagem do objeto estudado. A conexão estabelecida pelo indivíduo entre as diferentes representações contribui para a aprendizagem significativa, ou seja, a cada conversão o indivíduo tem a espontaneidade de acessar aspectos diferentes dos objetos representados. É essa aprendizagem significativa que contribui para construção do conhecimento matemático.

Conforme Santana et al. (2013), várias pesquisas apontam que, contrariamente ao que defende Duval, o ensino de fração tem, de certo modo, priorizado quantidades contínuas em frações, como o uso das pizzas e barras de chocolate.

[...] o ensino baseado em quantidades contínuas favorece o uso do procedimento de dupla contagem, ou seja, conta-se em quantas partes a fração foi dividida e em seguida contam-se as partes "tomadas" desta fração. Este procedimento interfere na compreensão da representação numérica fracionária, pois, em situações de ensino é comum formar esta representação pensando que o denominador são as partes em que a fração foi dividida e o numerador as partes tomadas do todo, favorecendo a percepção da fração como a sobreposição de dois números inteiros. (NUNES; BRYANT, 1997, apud SANTANA et al., 2013, p. 4).

Ainda, segundo Santana et al. (2013), o enfoque em procedimentos faz com que a compreensão do estudante se limite às operações e não aos conceitos, como segue:

[...] o ensino de operações que envolvem frações têm ênfase em aspectos procedimentais como o uso do mínimo múltiplo comum, sem a compreensão da relação deste procedimento com a equivalência de frações, por exemplo (NUNES, 2003, apud Santana et al., 2013, p. 5).

\section{Metodologia}

A metodologia utilizada para a coleta de dados nesta pesquisa consiste na aplicação de uma atividade de avaliação diagnóstica sobre o objeto matemático das frações. A avaliação foi elaborada dentro da perspectiva da TRRS, com o intuito de analisar o conhecimento prévio dos estudantes, bem como a utilização dos processos de tratamento e conversão da teoria.

As frações são abordadas em sala de aula desde o Ensino Fundamental, de modo que o professor é levado a apresentar este conteúdo em mais de uma representação, uma delas referente aos números racionais. De acordo com Maranhão e Igliori (2008), o número racional, quando introduzido no ensino fundamental, aparece representado em três tipos de registro: registro figural; (representação de partes de grandezas); registro simbólico (numérico ou algébrico); e no registro da língua natural. Na Figura 1, temos o quadro elaborado com as devidas representações: 
Figura 1 - Registros de representação e números racionais.

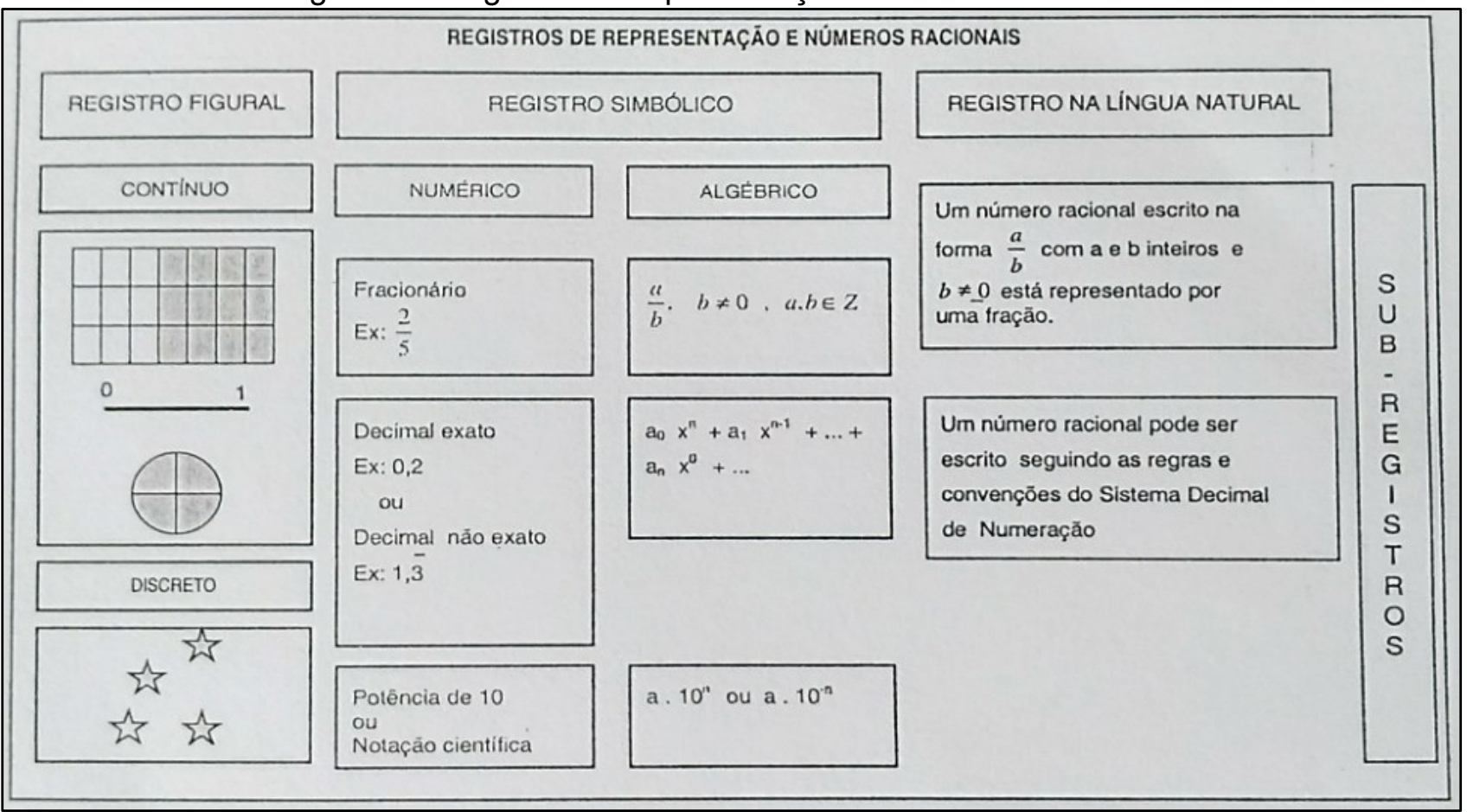

Fonte: Maranhão e Igliori (2008, p. 59).

A avaliação foi planejada, assim, de forma a constatar como os estudantes lidam com tratamentos e conversões envolvendo os registros fracionário, figural e decimal. Na atividade de tratamento - questão 1 - são apresentados os itens (a), (b), (c) e (d), no registro de frações, e os itens (e), (f), (g) e (h), no registro dos números decimais (Figura 2). Nessa questão, tem-se por expectativa que os estudantes procedam os cálculos dentro dos registros apresentados.

Figura 2 - Questão 1 da avaliação diagnóstica.

\begin{tabular}{|c|c|}
\hline $\begin{array}{l}\text { 1. Re solva as que stões com fraçõese núme ros de cimais: } \\
\text { a) } \frac{1}{2}+\frac{1}{4}= \\
\text { b) } \frac{2}{3}-\frac{1}{6}= \\
\text { c) } \frac{3}{5} \times \frac{5}{2}= \\
\text { d) } \frac{2}{5}: \frac{1}{10}=\end{array}$ & $\begin{array}{l}\text { e) } 0,9+0,01= \\
\text { f) } 0,3-0,2= \\
\text { g) } 2,25 \times 0,125= \\
\text { h) } 1,64: 4,1=\end{array}$ \\
\hline
\end{tabular}

Fonte: Elaboração dos autores (2017).

$\mathrm{Na}$ atividade de conversão - questão 2 - os itens (a), (b), (c), (d), (e) e (f) apresentam uma fração, representada em um dos três registros: fracionário, figural e número decimal (Figura 3). 0 estudante deverá então realizar a conversão para os outros dois registros solicitados. 
Figura 3 - Questão 2 da avaliação diagnóstica.

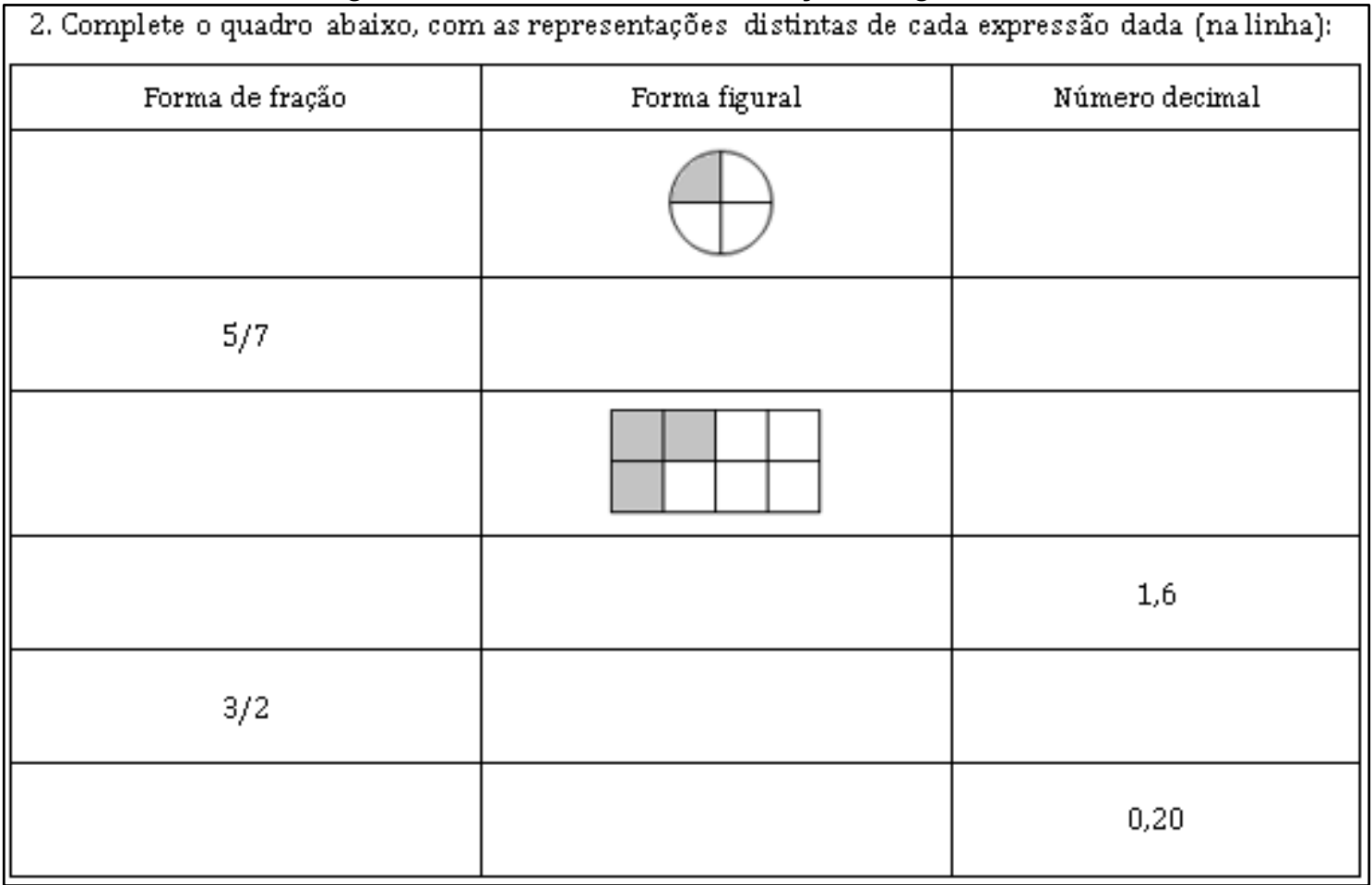

Fonte: Elaboração dos autores (2017).

A análise das resoluções foi realizada sobre aspectos da TRRS, focando, principalmente, nos processos em que se verificou algum erro no desenvolvimento das questões 1 e 2 .

\section{Resultados e Discussões}

A avaliação diagnóstica apresentada na metodologia foi aplicada com vinte e três estudantes do Ensino Fundamental, Médio e Superior. No Ensino Fundamental, a avaliação foi aplicada com oito estudantes da Escola Municipal de Educação Básica Albino Zanatta, da cidade de Jacinto Machado - SC, sendo dois estudantes do $7^{\circ}$ ano, três do $8^{\circ}$ ano e três estudantes do $9^{\circ}$ ano. Nos ensinos Médio e Superior, participaram quinze estudantes do Instituto Federal de Santa Catarina - IFSC, Campus Araranguá. No Ensino Médio, a avaliação foi aplicada com três estudantes do $1^{\circ}$ ano, três estudantes do $2^{\circ}$ ano e três estudantes do $3^{\circ}$ ano. Com os estudantes do Ensino Superior, mais precisamente do curso de Licenciatura em Física, a avaliação foi aplicada com três estudantes da $1^{\mathrm{a}}$ fase e três estudantes da $2^{\mathrm{a}}$ fase. Todos os estudantes participantes da pesquisa foram selecionados ao acaso pelos autores, de forma que os dados não destoassem da realidade.

Para a construção dos gráficos, as resoluções foram classificadas em "corretas" e "incorretas", de modo que os itens resolvidos parcialmente corretos ou não feitos foram considerados incorretos. A seguir, o Gráfico 1 apresenta a incidência de resoluções incorretas observadas nos três níveis de ensino. 


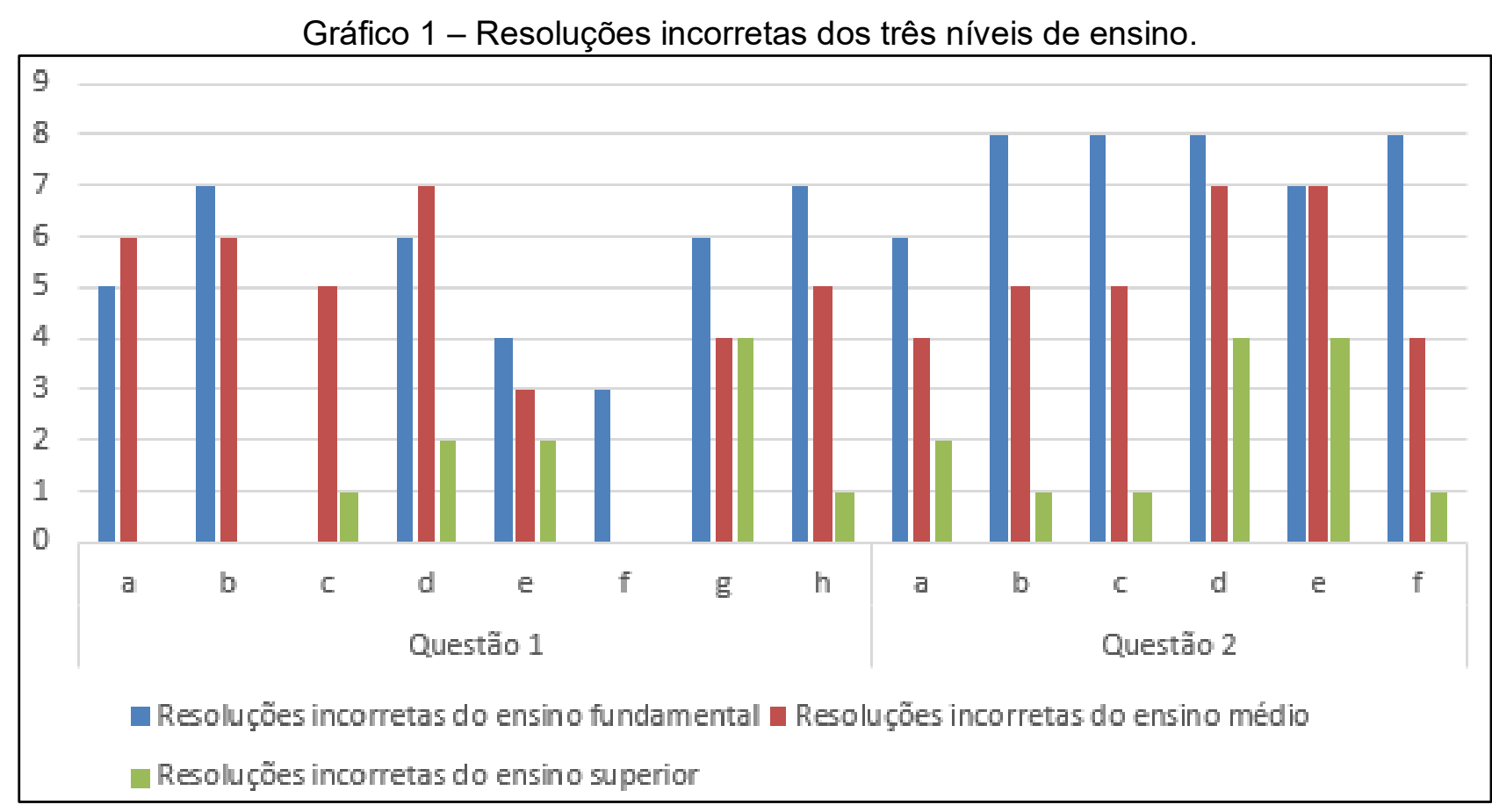

Fonte: Dados da pesquisa.

Como esperado, podemos observar que os dados (Gráfico 1) indicam que, com o aumento no nível da escolaridade, os estudantes apresentam maior domínio das operações solicitadas. Outro ponto que devemos ressaltar é o alto índice de erros em questões de conversão por parte dos estudantes de Ensino Fundamental, indicando que este tipo de atividade tem sido pouco abordada em sala de aula, justificando assim, com base na teoria de Duval, a dificuldade destes com o objeto.

$\mathrm{Na}$ sequência, iremos realizar uma análise acerca das respostas apresentadas na avaliação diagnóstica com o objetivo de verificar o que o estudante apresenta ter domínio, referente aos processos de tratamento e conversão, assim como verificar os erros na resolução dos itens, pois, em muitos casos, estes são justificados pela TRRS. Os resultados seguem a ordem: Ensino Fundamental, Ensino Médio e Ensino Superior.

\subsection{Ensino Fundamental}

Em relação aos itens (a), (b), (c) e (d) da questão 1, a maioria dos estudantes do $8^{\circ}$ e $9^{\circ}$ ano apresentaram dificuldade em proceder com o algoritmo para operar com frações, porém todos resolveram de "maneira correta" o item (c), de multiplicação de fração, já que esta se dá da mesma maneira que com os números naturais.

$\mathrm{Na}$ Figura 4, observando a resolução dos itens (a) e (b) dos estudantes, verificamos tratamentos distintos para a resolução dos itens. O estudante da esquerda resolve o item (a) indicando usar o mínimo múltiplo comum (ou a simplificação de frações). Já o estudante da direita resolve os itens (a) e (b) reduzindo as frações ao mesmo denominador, ou seja, encontrando frações equivalentes para a realização da operação. 
Figura 4 - Resoluções corretas com frações.

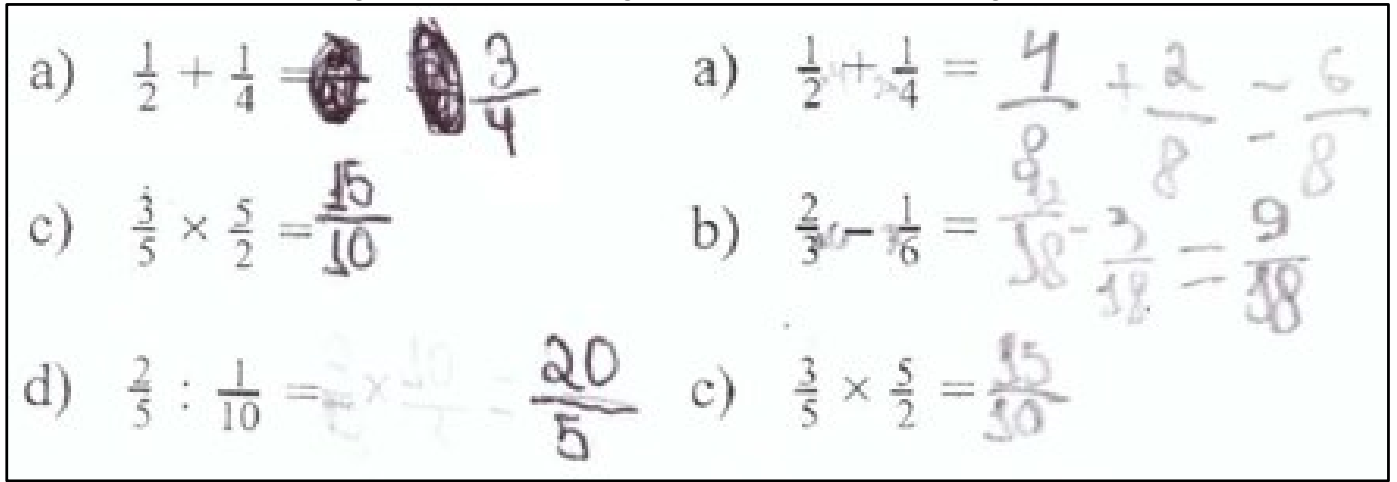

Fonte: Dados da pesquisa.

Como podemos observar na Figura 5, alguns estudantes resolvem operações com frações da mesma maneira com que estas são feitas com números naturais, ou seja, realizam uma operação termo a termo, indicando que não há a compreensão do conceito de fração e do sistema de representação. Ainda, devemos observar que o estudante da esquerda apresenta domínio parcial acerca da divisão de frações, pois realiza a inversão da segunda fração, mas não muda a operação.

Figura 5 - Resoluções incorretas com frações.

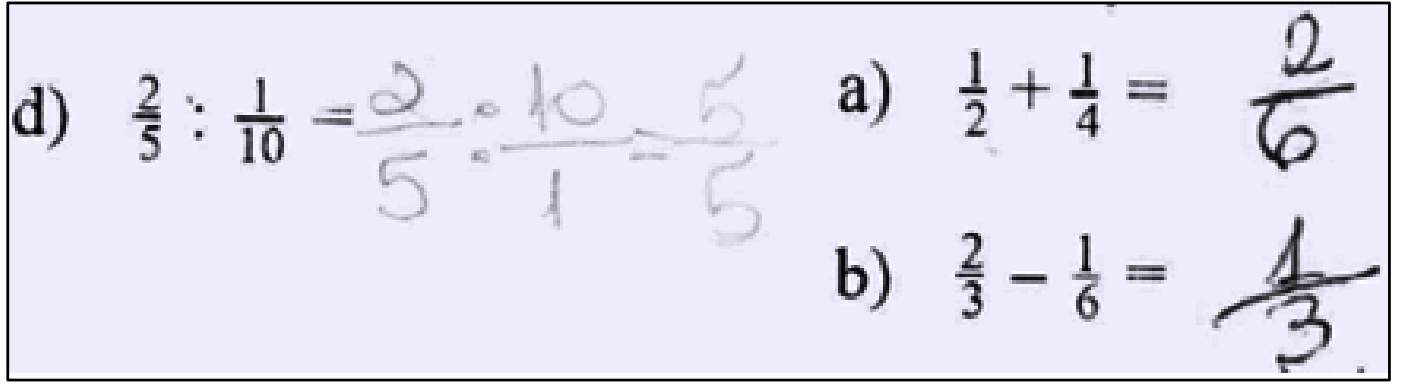

Fonte: Dados da pesquisa.

Continuando com a análise dos itens (e), (f), (g) e (h) da questão 1 , de modo geral, a incidência de acertos ocorre nos itens (e) e (f) de adição e subtração com números decimais. Porém, também observamos resoluções corretas nos itens $(\mathrm{g})$ e $(\mathrm{h})$, de multiplicação e divisão.

Figura 6 - Resolução incorreta com números decimais.

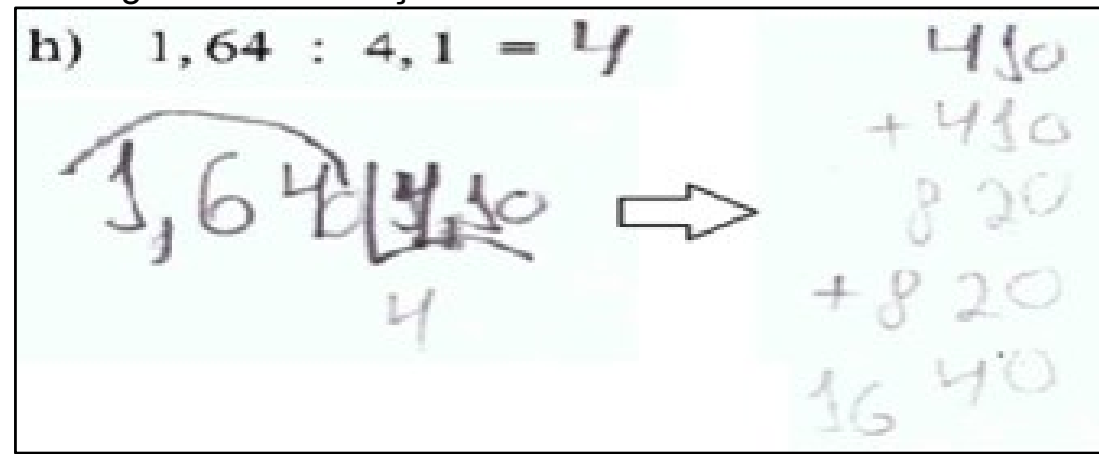

Fonte: Dados da pesquisa.

Observando o rascunho da resolução do item (h), exibida pelo estudante na Figura 6, assim como por outros estudantes, podemos observar que não há compreensão total acerca das operações com números decimais. Mas, o que nos chama a atenção é o fato de que o estudante 
busca encontrar o número de parcelas a somar para conseguir obter o resultado da divisão, ou seja, o número de vezes que o divisor "cabe" no dividendo, indicando assim o domínio do conceito de divisão com números decimais.

$\mathrm{Na}$ questão 2, dois estudantes resolveram de maneira correta o item (a). Os outros estudantes efetuaram a conversão correta para o registro fracionário, porém, no registro decimal, deixaram em branco ou apresentaram dificuldade na operação de divisão.

Observando a resolução exibida pelo estudante de baixo (na Figura 7), verificamos a dificuldade em representar o objeto matemático no registro decimal, quando o registro inicial é o figural ou o fracionário, uma vez que este foi encontrado. Isto nos chama a atenção pelo fato de o mesmo não fazer a correspondência da quantidade no registro decimal com os outros dois registros, ou seja, na conversão do registro figural para o fracionário o estudante deixa a entender que compreende que este representa um número menor que 1 , uma vez que faz a "parte do todo". Já na representação do mesmo no registro decimal apresenta um valor maior do que 1.

Figura 7 - Resoluções parcialmente corretas dos itens (a) e (c).

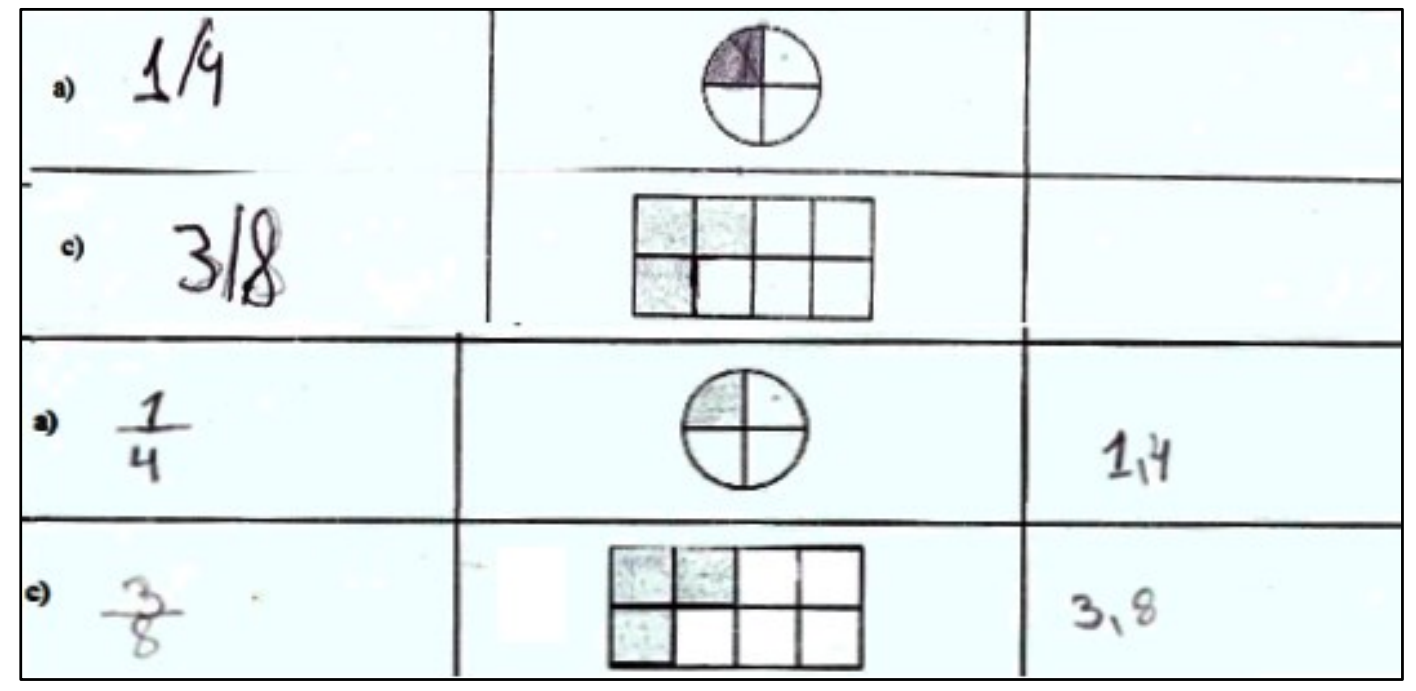

Fonte: Dados da pesquisa.

Nos itens (b) e (e), três estudantes efetuaram a conversão correta apenas para o registro figural e um estudante efetuou a conversão correta apenas para o registro decimal, os demais estudantes deixaram em branco ou operaram os cálculos de maneira incorreta.

A dificuldade em proceder com os cálculos no registro decimal é uma tendência que segue na resolução dos estudantes do Ensino Fundamental. Analisando a resolução dos itens (b) e (e) do estudante (Figura 8), constatamos que o mesmo não conclui o item no registro decimal. Verificamos, na resolução do item (e), que o registro decimal é uma representação à parte, pois o estudante não aparenta realizar uma relação desta representação com as outras, uma vez que apresenta um valor menor que 1 e, principalmente com sua representação figural, ele deixa claro entender que a fração é uma parte inteira mais metade desta. 
Figura 8 - Resoluções parcialmente corretas dos itens (b) e (e).

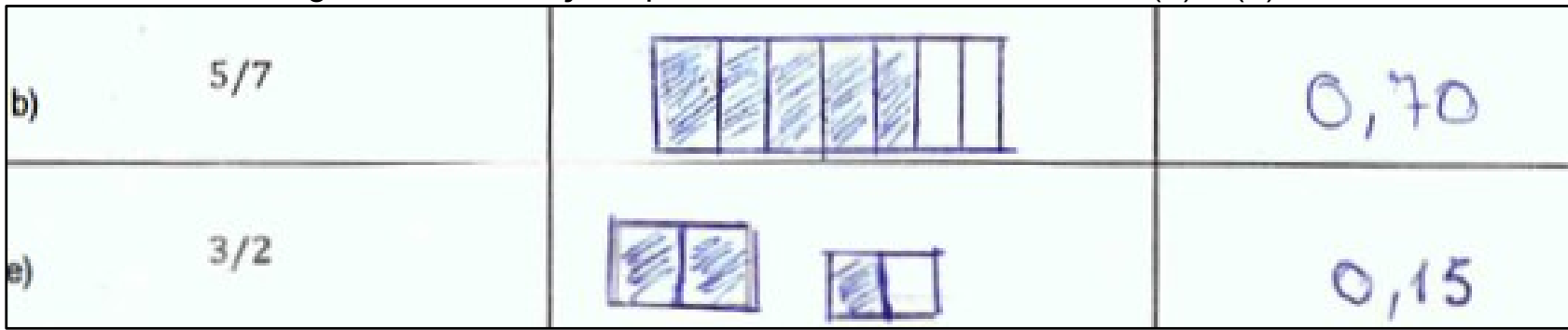

Fonte: Dados da pesquisa.

Outro caso que aparece na resolução dos estudantes é a desproporcionalidade na divisão da figura no registro figural. Isto ressalta que o estudante pode não ter compreensão conceitual de divisão, ou seja, de que a divisão é feita em partes iguais. Na Figura 9, temos a conversão do registro fracionário para o figural exibida por um estudante que segue o erro na divisão e, assim como outros estudantes, deixa o registro decimal em branco.

Figura 9 - Resoluções incorretas dos itens (b) e (e).

\begin{tabular}{|l|l|l|}
\hline b) $5 / 7$ & \\
\hline e) $3 / 2$ & & \\
\hline
\end{tabular}

Fonte: Dados da pesquisa.

Nos itens (d) e (f), destacamos uma resolução (Figura 10), pois o estudante realiza a conversão errada a partir do registro decimal, mas apresenta os dois outros registros, figural e fracionário, em formas equivalentes, ou seja, a conversão de um para o outro é correta.

Figura 10 - Resolução parcialmente incorreta do item (f).

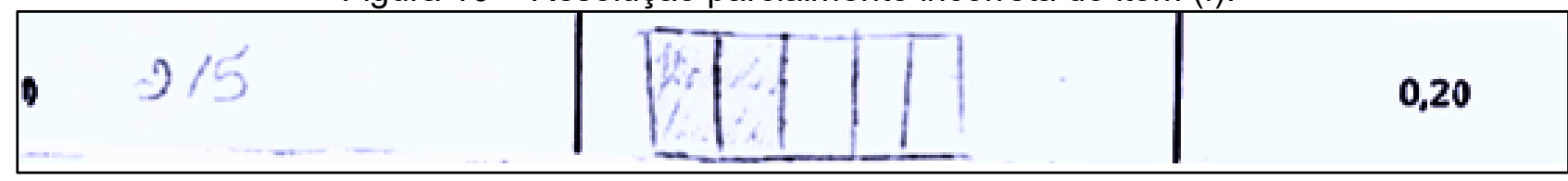

Fonte: Dados da pesquisa.

Como verificamos, existe uma grande dificuldade de os estudantes do Ensino Fundamental procederem com as operações no registro decimal. As conversões do registro fracionário/figural e figural/fracionário, de modo geral, são compreendidas pelos estudantes. Porém, na conversão das representações figural, ou fracionária, para o registro decimal, o estudante não consegue efetuar a divisão com resultado decimal. De modo geral, a maioria dos estudantes não relaciona a representação decimal do objeto representado com o registro figural ou fracionário. Além disso, os estudantes apresentam dificuldade em operar com números decimais, fato constatado pela dificuldade nos tratamentos com números decimais envolvendo as quatro operações. 
Conforme Maranhão e Igliori (2008), em geral, no Ensino Fundamental, as conversões são pouco usadas e, quando usadas, priorizam um sentido.

É importante destacar que o conhecimento das regras de correspondência entre dois registros pode não ser suficiente para mobilizá-los e utilizá-los simultaneamente. Um aluno pode saber, por exemplo, que deve dividir 1 por 4 para obter a representação decimal do racional $1 / 4$, mas pode ser que não reconheça 0,25 como outro representante do mesmo número racional. (MARANHÃO; IGLIORI, 2008, p. 60).

Esta dificuldade na compreensão (e na coordenação) entre os registros pode estar atrelada à confusão que o estudante faz entre o objeto representado e a sua representação.

\subsection{Ensino Médio}

$\mathrm{Na}$ questão 1, observamos que um único estudante simplificou os resultados, apresentando, assim, maior domínio dos conceitos envolvendo os registros de frações. O item (c), multiplicação de fração, ainda é a questão com maior número de acerto, talvez pela similaridade com que a operação é realizada como com os números naturais.

Observando a Figura 11, como já foi verificado nas resoluções anteriores, existe uma tendência de os estudantes realizarem as quatro operações com frações como se estivessem operando com números naturais. A resolução da esquerda (Figura 11) chama atenção pelo fato de que o mesmo realiza uma multiplicação "cruzada", talvez seguindo a "direção" do sinal da operação.

Figura 11 - Resoluções incorretas com frações.

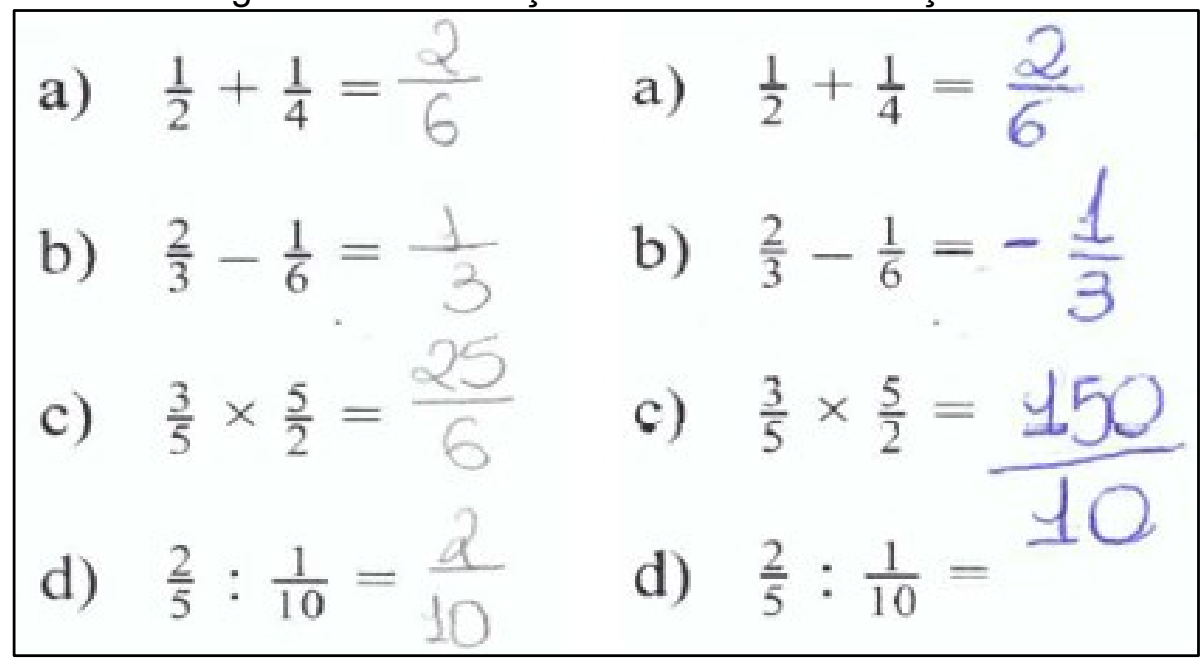

Fonte: Dados da pesquisa.

Continuando com a questão 1 , nos itens (e) e (f), verificamos que mais da metade dos estudantes resolveu de maneira correta o item (e), enquanto o item (f) foi resolvido de maneira correta por todos os estudantes. Nos itens $(\mathrm{g})$ e $(\mathrm{h})$, três estudantes resolveram corretamente os dois itens, outros dois estudantes resolveram de maneira correta apenas o item (g) e um estudante resolveu de corretamente o item (h). Entretanto, o item (h), assim como no Ensino Fundamental, foi o item entre as operações com números decimais em que mais se verificou 
resoluções incorretas. A dificuldade dos estudantes, de modo geral, aparenta estar em proceder com os algoritmos da divisão, que os mesmos não dominam com os números decimais.

Figura 12 - Resoluções incorretas com número decimais.

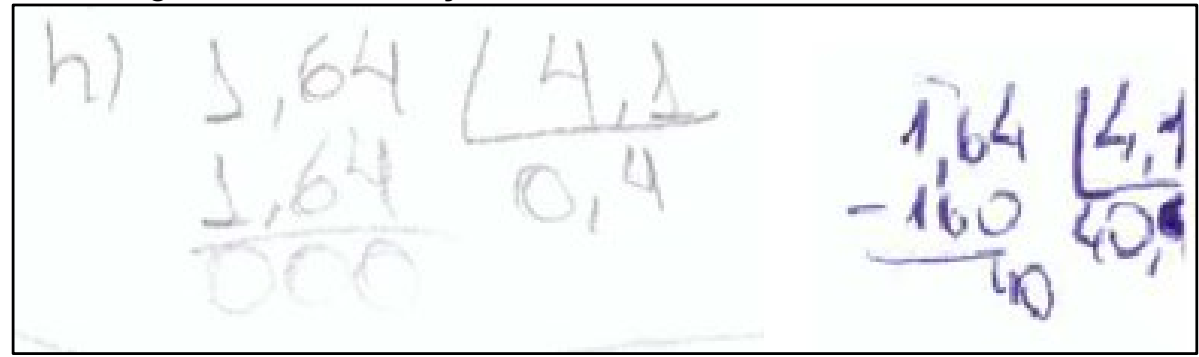

Fonte: Dados da pesquisa.

$\mathrm{Na}$ questão 2, dois estudantes resolveram de maneira correta todos os itens. Um estudante resolveu corretamente os itens (d), (e) e (f), e outro estudante conseguiu resolver os itens (a), (b), (c), e (f). Um estudante não conseguiu concluir nenhum dos itens da questão. Na Figura 13, segue o recorte de algumas resoluções parcialmente corretas dos itens citados.

Figura 13 - Resoluções parcialmente corretas dos itens (a) e (c).

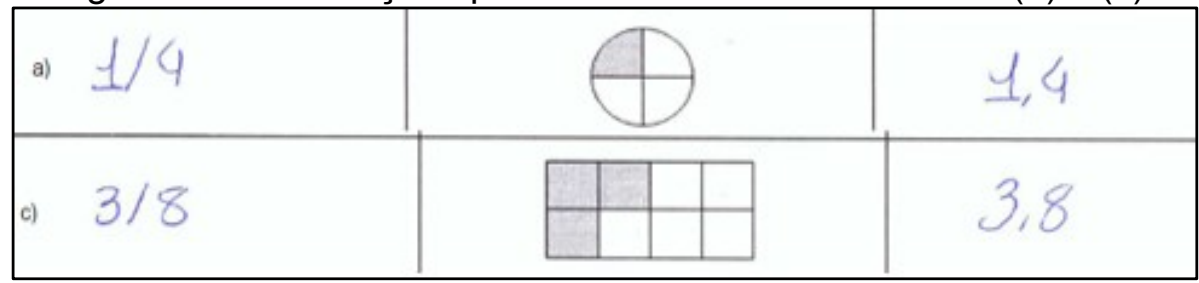

Fonte: Dados da pesquisa.

Podemos afirmar que há uma tendência, como fora verificado com o Ensino Fundamental, na não compreensão pela maioria dos estudantes em operar números decimais e, também, a não identificação do objeto matemático representado no registro figural, ou fracionário, com o mesmo objeto no registro decimal. O que se observa, como já foi dito, é que há uma dissonância entre o que se consegue realizar com os registros fracionário e figural em relação ao registro decimal.

Outro caso (Figura 14) que aparece na resolução dos estudantes, aqui representado por dois estudantes, é a conversão correta entre registro decimal e registro fracionário, mas incorreta destes registros para o figural. Os mesmos não aparentam perceber que existe a parte inteira no registro figural, muito clara no registro decimal, e fica clara a inversão da compreensão na noção de "parte do todo" da fração para a representação figural.

Figura 14 - Resoluções parcialmente corretas.

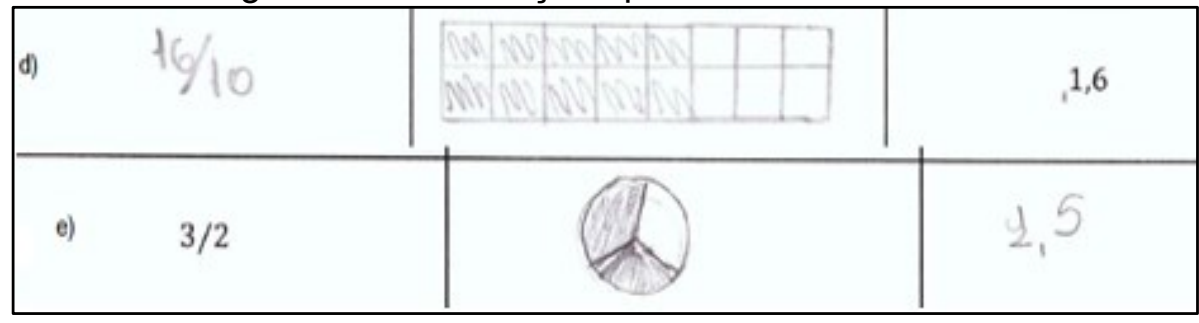

Fonte: Dados da pesquisa. 
Os problemas que identificamos aqui podem ser explicados pela fala de Duval $(2008, p$. 21), quando este afirma que o sucesso de muitos estudantes no estudo da Matemática, está atrelado ao uso de apenas um registro, ou poucos registros. Isso se dá devido ao "enclausuramento do registro", que impede o estudante de reconhecer o mesmo objeto em mais de uma representação. Para o autor, é isso que limita a capacidade de compreensão e aprendizagem, visto que há uma limitação na utilização de conhecimentos já adquiridos, que possibilitariam adquirir novos conhecimentos em Matemática.

\subsection{Ensino Superior}

Primeiramente, devemos observar que, no Ensino Superior, o índice de respostas corretas é muito maior do que os apresentados na educação básica (ensinos Fundamental e Médio). Isto provavelmente se dá por dois motivos, o primeiro seria o fato de que estes estudantes já passaram por toda a formação básica, de um ensino que presa comumente pela revisão de conceitos já aprendidos; e o segundo sendo o fato de que o curso em que foi aplicada a avaliação diagnóstica é de licenciatura em Física, em que os estudantes têm um grande contato com a Matemática, não apenas do Ensino Superior.

$\mathrm{Na}$ questão 1, constatamos com a correção que apenas dois dos estudantes resolveram incorretamente os itens (c) e (d). Ainda na questão 1, um estudante não apresentou resolução dos itens $(\mathrm{e}),(\mathrm{g})$ e $(\mathrm{h})$. Outros dois estudantes resolveram de maneira incorreta o item $(\mathrm{g})$, já outro estudante resolveu de maneira incorreta os itens (e) e (g).

Três dos estudantes simplificaram os resultados dos seus cálculos, mas um dos estudantes, além de simplificar os resultados, apresentou a solução em dois registros. Devemos ressaltar aqui que esse último estudante citado apresenta grande domínio do objeto da pesquisa, uma vez que, na resolução dos itens $(\mathrm{g})$ e (h), ele efetua a conversão dos números decimais para o registro fracionário e, em seguida, realiza a operação neste registro, o que talvez seja mais "simples" ou "familiar" para o estudante efetuar o cálculo. Segue (Figura 15) o recorte da resolução da questão 1 deste estudante.

Figura 15 - Resoluções corretas na questão 1.

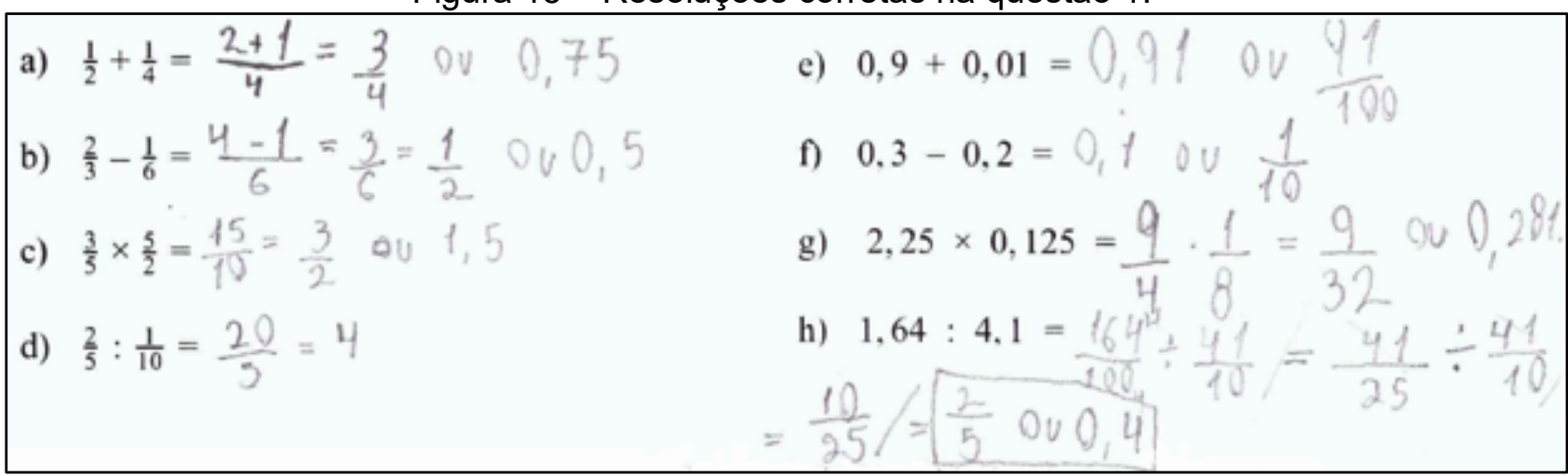

Fonte: Dados da pesquisa. 
$\mathrm{Na}$ questão 2, a maioria dos estudantes procedeu de forma satisfatória às conversões. Dois estudantes resolveram de maneira incorreta os itens (d) e (e), pois ambos não apresentam o registro figural. Um estudante (Figura 16) representa somente as partes tomadas na divisão, o que conceitualmente não está errado, uma vez que este apresenta qual seria a parte inteira da fração e as partes tomadas estão em proporção com a "unidade".

Figura 16 - Resolução correta dos itens (d) e (e).

\begin{tabular}{|l|r|r|}
\hline$\frac{8}{5}$ & 1,6 \\
\hline e) $3 / 2$ & & 1,5 \\
\hline
\end{tabular}

Fonte: Dados da pesquisa.

Outro estudante (Figura 17) entende que a fração em questão é mista, porém, no registro figural, apresenta a parte inteira desproporcional à parte fracionada, o que indica que este estudante possui a compreensão de que a fração representa um inteiro mais uma parte não inteira. No entanto, sua resposta indica que não existe a compreensão de que a parte inteira e não inteira são de mesma proporção.

Figura 17 - Resolução parcialmente correta dos itens (d) e (e).

\begin{tabular}{|l|l|c|}
\hline $8 / 5$ & and & 1,6 \\
\hline $3 / 2$ & e) & 1,5 \\
\hline
\end{tabular}

Fonte: Dados da pesquisa

\section{Considerações Finais}

A compreensão dos números racionais, especificamente na forma fracionária, é essencial para o estudante. De acordo com Maranhão e Igliori (2008), a não compreensão deste objeto acarreta em sérios prejuízos na aprendizagem nos diversos campos da Matemática.

A teoria desenvolvida por Duval pode ser utilizada como uma ferramenta para entender a importância dos diversos registros semióticos e como proceder com a diversidade de representações de um mesmo objeto matemático. Além disso, ela nos possibilita compreender os erros cometidos pelos estudantes e inferir sobre possíveis motivos que os levam a errar, podendo assim rever metodologias de ensino. A partir da análise da avaliação diagnóstica, constatamos a 
importância que deve ser dada à TRRS no processo de ensino e aprendizagem em Matemática, uma vez que percebemos que não há compreensão total do objeto das frações.

De forma geral, também constatamos que é de grande importância que professores se atenham aos possíveis registros que podem ser utilizados em sala de aula. Alguns questionamentos que levantamos aqui, referentes ao processo de ensino de frações, são: é dada a devida importância aos processos de conversão em sala de aula? O estudante consegue entender que um número decimal é uma fração e consegue representá-lo dessa forma? Em relação aos números decimais maiores que um ou frações mistas, o estudante consegue entender que estes dois têm a mesma propriedade (possui a parte inteira)? $O$ estudante consegue representar uma fração mista no registro figural (parte inteira mais parte do todo)?

Com a análise da avaliação diagnóstica, verificamos que, no Ensino Fundamental, de modo geral, os estudantes apresentam grande dificuldade em representar a fração no registro decimal. Diante desta constatação, podemos inferir que o processo de conversão tende apenas ao sentido fracionário e figural e pouco se trabalha a conversão para o registro decimal.

No Ensino Médio, este padrão segue de modo menos expressivo, mas ainda é visível a dificuldade em representar a fração no registro decimal, porém, os dados apresentam com mais expressividade a dificuldade em representar a fração no registro figural. Também é possível inferir que, mesmo no Ensino Médio, o estudante ainda não compreende as diversas representações de uma fração e o seu conceito, uma vez que, no processo de conversão, são bem-sucedidos apenas nas representações fracionária e decimal.

Diante destas constatações, podemos supor que as concepções da TRRS ainda são aplicadas, mesmo que de modo implícito, de maneira superficial no Ensino Fundamental e Médio. Esta suposição emerge uma vez que as dificuldades apresentadas no Ensino Fundamental e Médio aparecem com menor expressividade no Ensino Superior, porém os erros em geral são semelhantes, especialmente na representação decimal e na representação figural da fração mista.

Assim, como a teoria ressalta que o sucesso da aprendizagem Matemática está na articulação entre os diferentes registros do mesmo objeto, este trabalho aponta que o ensino de frações ainda merece muita atenção por parte de professores e pesquisadores, uma vez que os dados indicam que, aparentemente, não há um domínio total dos registros deste objeto, assim como das conversões e tratamentos entre frações e seus registros.

\section{Referências}

BOYER, C. B. História da Matemática. Trad. Elza F. Gomide. São Paulo: Editora da Universidade de São Paulo - Editora Edgard Blücher Ltda, 1974.

DUVAL, R. Registros de representações semióticas e funcionamento cognitivo da compreensão em matemática. In: MACHADO, Silvia D. A. Aprendizagem em Matemática: Registros de Representação Semiótica. Campinas-SP: Papirus, p. 11-33, 2008. 
DUVAL, R. Registros de representação semiótica e funcionamento cognitivo do pensamento. Tradução: MORETTI, M.T. Revemat. Florianópolis, v. 7, n. 2, p. 266-297, 2012.

MARANHÃO, M. C. S. A.; IGLIORI, S. B. C. Registros de representação e números racionais. In: MACHADO, Silvia D. A. Aprendizagem em Matemática: Registros de Representação Semiótica. Campinas: Papirus, p. 57-70, 2008.

MORETTI, M.T. O papel dos registros de representação na aprendizagem de Matemática.

Contrapontos. Itajaí-SC, ano 2, n. 6, p. 343-362, 2002.

PANTOJA, L. F. L.; CAMPOS, N. F. da S. C.; SALCEDOS, R. R. C. A Teoria dos Registros de Representação Semióticas e o estudo de sistemas de equações algébricas lineares. In: VI Congresso Internacional de Ensino de Matemática. Anais... Canoas-RS, 2013.

SANTANA, L. E. L.; LIMA, L. H. M.; SILVA, S. H. da; OLIVEIRA, B. P. de. Fração e seus diferentes registros de representação semiótica: uma análise da percepção de futuros pedagogos. In: XI ENEM - Encontro Nacional de Educação Matemática. Anais... Curitiba-PR, 2013. 